\title{
A Study on the Epidemiological and Serotype Pattern of Dengue Outbreak in Sikkim
}

Karma Doma Bhutia*, Pema Yoden Bhutia, Tara Sharma and Shrijana Gurung

STNM Hospital, Gangtok, Sikkim 737101, India

*Corresponding author: Karma Doma Bhutia, STNM Hospital, Gangtok, Sikkim 737101, India, Tel: 08145891089; E-mail: karmabhutia78@yahoo.com

Received date: October 11, 2018; Accepted date: November 19, 2018; Published date: November 25, 2018

Copyright: (C) 2018 Bhutia KD, et al. This is an open-access article distributed under the terms of the Creative Commons Attribution License; which permits unrestricted use; distribution; and reproduction in any medium; provided the original author and source are credited.

\author{
Abstract \\ Introduction: The outbreak of Dengue was reported from South Sikkim (Jorethang) and East Sikkim (Rangpo) \\ in September 2017.
}

Objective: To confirm the dengue outbreak by ELISA to find the serotype of Dengue virus responsible for the outbreak in Sikkim.

Materials and Methods: Serum samples from the two districts (outbreak areas) were tested by NS1Ag ELISA and IgM ELISA. The NS1Ag positive samples were sent to ICMR unit, NICED (National Institute of Cholera and Enteric disease), Kolkata for serotyping.

Results: The most common age group affected was 16-30 years. Males were more affected than females. The outbreak occurred in the month of September 2017. The predominant serotype was DEN2 few cases of DENV 1 , DENV3 and DENV4 were also found.

Conclusion: Recent outbreak has established Dengue as an important disease of concern in Sikkim. Young age groups were more affected. Serotype 2 was the major circulatory serotype.

Keywords: Epidemiological; Dengue outbreak; Serotype pattern

\section{Introduction}

Dengue virus belongs to the genus Flavivirus in the family Flaviviridae. It is a positive sense RNA virus that is composed of three structural proteins, an envelope glycoprotein, and seven non-structural proteins. It is transmitted mainly by Aedes aegypti and also by Aedes albopictus mosquitoes. Dengue fever was defined as an acute febrile illness accompanied by myalgia, retro-orbital pain, joint pain or rash. Dengue fever is currently considered re-emerging infectious disease because of the dramatic increase in recent decades with an estimated annual occurrence of 100 million new cases in tropical and Subtropical regions of the world [1,2]. Dengue virus has five distinct serotypes DV1, DV2, DV3, DV4 and DV5 [3]. Infection with one serotype confers immunity to that particular serotype but protection against other serotypes is only partial and transient [4-6]. Early and accurate diagnosis and management can reduce the mortality and morbidity of DHS and DSS. Early laboratory confirmation is valuable because some patients may deteriorate rapidly resulting in death [7].

The first report of Dengue fever in India was in 1946. After almost 20 years, an epidemic occurred in 1963-1964 in Kolkata [8-10]. It gradually spread to involve North India in 1967-1968 and South India $[11,12]$. All four serotypes of the virus were reported from South India. 13 The first major outbreak of Dengue Fever/ Dengue Hemorrhagic Fever occurred in Delhi in 1996 where 10,252 cases and 423 deaths were reported [13]. This outbreak was caused by DENV-2, genotype IV strain of the virus [14]. Similar strains of the DEN-V 2 were also reported from Gwalior and South India, indicating that the predominant strain in India was DENV-2 [15]. In the post-epidemic period in Delhi in 1997, DENV 1 was also seen in the circulation. A dramatic increase in outbreaks occurred in India where all four serotypes are present hinting towards hyperendemicity of dengue in India $[16,17]$. The country faced another outbreak in 2003 by serotype 3 . At present all the four serotypes are present in Indian circulation but the predominant serotype keeps changing.

Sikkim is a tiny hilly state in northeast India in the foothills of the Himalayas. It is situated in $27.53 \mathrm{~N} 88.51 \mathrm{E}$. It has carried elevations ranging from $300 \mathrm{~m}$ to $8583 \mathrm{~m}$ above sea level consisting of lower, middle and upper hills, alpine zones and snowbound land. The total geographical area is 7096 sq.kms. The climate varies from tropical, subtropical to temperate to Alpine zones. It experiences heavy rainfall, monsoon starts from May to September. The outbreak occurred in Jorethang (South Sikkim) and Rangpo (East Sikkim) in September 2017. Jorethang is a small town in South in the foothills at an altitude of $322 \mathrm{~m}$ above sea level while Rangpo is in East Sikkim, a town bordering West Bengal situated at an altitude of $1300 \mathrm{~m}$ [18].

\section{Materials and Methods}

\section{Study population}

The study was done in samples collected from dengue outbreak areas in Sikkim. This study was approved by the Institution ethics committee.

\section{Inclusion criteria:}


1) Samples from outbreak affected areas suspected of dengue fever for ELISA

2) NS1Ag positive samples for serotyping

\section{Exclusion criteria:}

1) Unlabelled, hemolysed and lipemic samples were excluded

2) NS1Ag positive serum sample whose volume was inadequate could not be sent for serotyping

There was a sudden increase in fever cases in September 2017 in East Sikkim, Rangpo and South Sikkim, Jorethang. 348 serum samples of Dengue suspected cases were received from the outbreak areas in the cold chain. The samples were sorted according to the day of fever, Samples with less than five days of fever $(n=283)$ were tested by NS1Ag ELISA,( Dengue Early ELISA, Panbio, Standard Diagnostics, Inc., Gyeonggi-do, Republic of Korea). Serum samples of more than five days of fever $(n=65)$ were tested by IgM capture ELISA (Mac ELISA by NIV National Institute of Virology, Pune, India). Manufacturer's instructions were strictly followed.

$76 \mathrm{NS} 1 \mathrm{Ag}$ positive samples were sent for serotyping to ICMR unit, National Institute of Cholera and Enteric Disease (NICED), Kolkata. Dengue serotyping was done by Reverse Transcriptase Polymerase Chain Reaction RT PCR according to Lanciotti et al. [19].

\section{Results}

348 serum samples were received from the outbreak areas in the cold chain. ( $\mathrm{n}=263$ from East Sikkim, $\mathrm{n}=85$ cases from South Sikkim). The samples were sorted according to the day of fever. Of the total of 348 samples, 283 samples were less than five days of fever, 65 samples were more than five days of fever. 283 samples were tested by NS1Ag ELISA, out of which 155 samples were positive (54.77\%). 65 samples were tested by IgM ELISA out of which ten were positive (15.38\%) (Table 1).

\begin{tabular}{|l|l|l|l|}
\hline District & $\begin{array}{l}\text { Total samples } \\
\text { received }\end{array}$ & NS1Ag positive & IgM ELISA positive \\
\hline East Sikkim & 263 & $76 / 198(38.38 \%)$ & $10 / 65(15.38 \%)$ \\
\hline South Sikkim & 85 & $79 / 85(92.94 \%)$ & $\begin{array}{l}\text { No samples<5 days } \\
\text { of fever }\end{array}$ \\
\hline Total & 348 & 155 & 10 \\
\hline
\end{tabular}

Table 1: District-wise distribution of Dengue cases.

The most affected age group were $16-30$ years $(70 / 155,45.16 \%)$ followed by $31-45$ years $(34 / 155,21.93 \%)$. More males $(n=80,51.61 \%)$ were affected as compared to females $(n=75,48.38 \%)$. The outbreak occurred in the month of September-November 2017. There were no reported cases after December 2017 (Figure 1).

Of 155 NS1Ag positive samples, 76 samples were sent for serotyping.79 samples could not be sent due to insufficient volume. 76 samples (46 from East Sikkim and 30 from South Sikkim) were sent to ICMR unit, National Institute of Cholera and Enteric Disease (NICED), Kolkata .75 samples were positive for NS1Ag, one sample was negative. In 65 samples out of 75 , DEN V 2 was found. The predominant serotype detected in the outbreak in Sikkim was DENV 2. $(65 / 75,86.66 \%),(n=39 / 45$ from East, $n=26 / 30$ from South $)$. Other serotypes found were DENV $4=$ four samples (from East Sikkim),
DENV 3 =two samples from (South Sikkim), DENV $1=$ four samples (two each from two districts). The data of East and south Sikkim regarding DENV 2 and other serotypes were analyzed by Fisher's exact test. The two-sided $\mathrm{P}$ value is 1.0000 , considered not significant.

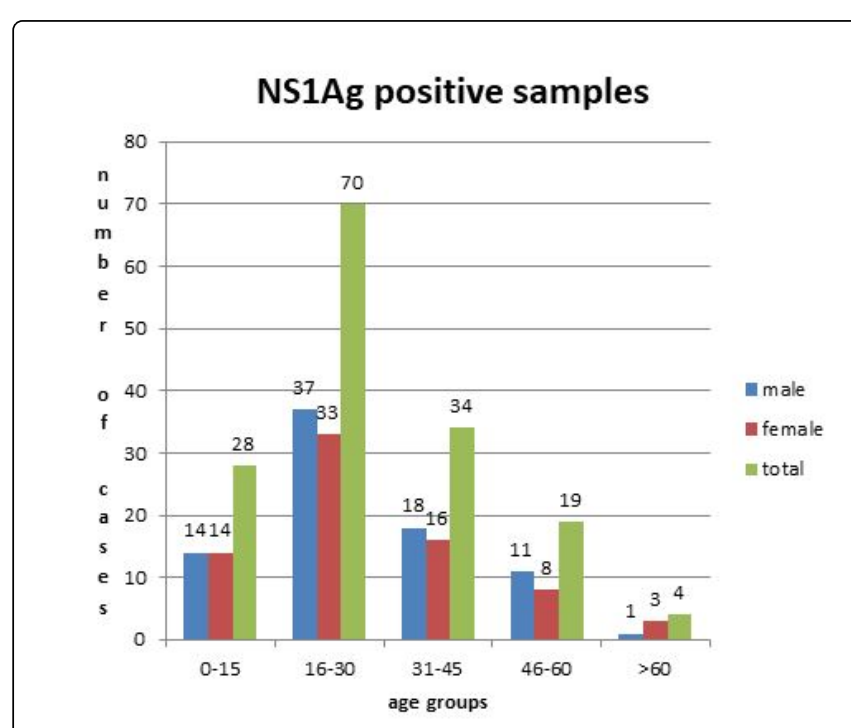

Figure 1: Age and sex distribution of NS1Ag positive samples.

\section{Discussion and Conclusion}

This paper reports the serotype of Dengue virus in September 2017 outbreak in Sikkim. Till date, no study has reported serotype of Dengue virus in Sikkim. The foothills of Sikkim have a lower altitude, a Sub-tropical climate which favors the breeding of mosquitoes. With the population growth and ease of travel, dengue has become a major concern in fever cases during the post-monsoon period.

In India, DENV 1, 2, 4 serotypes were the most common circulating strains from 2008 until 2010 after which DENV 3 rose and led to massive dengue outbreak in Kolkata with more number of DHF and DSS cases in 2012 [20].

283 samples from outbreak areas with fever less than five days were tested by NS1Ag ELISA, 155 (54.77\%) samples were positive. NS1Ag (the non-structural protein) is abundant in the serum of patients in early stage of infection from one to nine days. Kumarasamy et al. $[20,21]$ compared the use of NS1 ELISA with viral isolation in cell culture and RT PCR assay and concluded that NS1 Ag detection may be an appropriate marker of acute DENV infection [21].

The most affected age group was 16-30 years (70 cases out of 155 , $45.16 \%$ ) followed by 31-45 years age group (34 cases out of 155 , 21.93\%). Males were affected slightly more than females (80:75). Ukey et al. [22] showed a 15-30 years age group as highly affected with male predominance which was similar to our findings. Gupta et al. [23], Chakravarti and Kumaria et al. [24] also found the most affected age group as 21-30 years.

The outbreak occurred in the post-monsoon period. This could be explained by the fact that the water in the rainy season gets stagnant which favors the breeding of vector mosquito. This finding is consistent with studies by Hati et al. [25] and Gunasekaran et al. [26] which also showed most of the cases in the post-monsoon period. 
Clustering of Dengue cases was seen in the postmonsoon season in a study by Gibbons [27].

DENV2 is seen as the predominant serotype in this outbreak. Report of DEN V 2 in Assam and Nagaland appeared during the nineties [28] DENV2 was isolated during the epidemic of Dengue in rural and urban areas of Gujarat during 1988 and 1989 [29]. DV2 was the predominant serotype circulating in northern India including Delhi, Lucknow, and Gwalior [30,31] DENV 2 was also reported from Mandali village in Madhya Pradesh [32]. DEN 2 was also reported from south India in Kerala along with DENV 3 [33]. Co-infection with multiple serotypes have been reported from places where multiple serotypes co-circulates [34] Though no cases from our study had coinfection, the existence of multiple serotypes in the circulation could lead to co-infection in future dengue outbreaks.

This is the first report of Dengue serotype in the northeast state, Sikkim. This study is also the first to report co-circulation of 4 types of dengue virus serotypes in an outbreak in Sikkim. Dengue serotype 4 has been isolated from 4 cases from samples of Singtam and Rangpo. DENV4 is a rare serotype which has recently been spreading through the country $[35,36]$. This study indicates the spread of DEN 4 serotype in the northeastern part of India, in Sikkim. Reports regarding the association of DEN 4 serotype with severe cases and its high rate of transmission as a cause of concern [37].

\section{Limitation of this Study}

Genotyping could not be done.

\section{References}

1. Guzman MG, Kouri G (2002) Dengue: An update. Lancet Infect Dis 2: $33-42$.

2. Gubler DJ (2011) Dengue, urbanization, and globalization: The unholy trinity of the 21st century. Trop Med Health 39: 3-11.

3. Mustafa MS, Rasotgi V, Jain S, Gupta V (2015) Discovery of the fifth serotype of Dengue virus (DENV-5): A new public health dilemma in Dengue control. Med J Armed Forces India Jan 71: 67-70.

4. WHO (2013) TDR Global alert and response Dengue/Dengue Haemorrhagic Fever Geneva: World Health Organisation.

5. Halstead SB (1974) Etiologies of the experimental dengues of Siler and Simmons. An J Trop Med Hyg 23: 974-982.

6. Wilder Smith A, Ooi EE, Vsudevan SG, Gubler DJ. Update on Dengue: Epidemiology, Virus evolution, Antiviral drug and vaccine development. Curr Infect Dis Rep 12: 157-164.

7. Kumar A, Sharma SK, Padbidri VS, Thakare JP, Jain DC, et al. (2001) An outbreak of dengue fever in rural areas of northern India. J Commun Dis 32: 22-27.

8. Gupta E, Dar L, Kapoor G, Broor S (2006) The changing epidemiology of dengue in Delhi, India. Virol J 3: 92-96.

9. Ramakrishnan SP, Gelfand HM (1964) Bose PN, Sehgal PN, Mukharjee RN. The epidemic of acute haemorrhagic fever, Calcutta: Epidemiological inquiry. Indian J Med Res 52: 633-650.

10. Sarkar JK, Pavri KM, Chatterjee SN, Chakravarty SK, Anderson CR (1964) Virological and serological studies of cases of haemorrhagic fever in Calcutta. Indian J Med Res 52: 684-691.

11. Balaya S, Paul SD, D' Lima LV, Pavri KM (1969) Investigations on an outbreak of dengue in Delhi in 1967. Indian J Med Res 57: 767-774.

12. Ghosh BN (1968) A Study on the epidemic of Dengue like fever in Pondicherry (1964-65 and 1965-66) Indian Med Assoc. 51: 261-264.

13. Karamchandani PV (1946) Dengue group of fevers in India. Lancet 1: 92.
14. Singh UB, Maitra A, Broor S, Rai A, Pasha ST, et al. (1999) Partial nucleotide sequencing and molecular evolution of epidemic causing dengue 2 strains. J Infect Dis 180: 959-965.

15. Dash PK, Parida MM, Saxena P (2004) Emergence and continued circulation of Dengue-2 (Genotype IV) virus strains in northern India. J Med Virol 74: 314-322.

16. WHO (2009) Dengue guidelines for diagnosis, treatment and prevention and control. 2nd Edition Geneva; WHO. pp: 1-44.

17. Saha K, Ghosh M, Firdaus R, Biswas A, Seth B, et al. (2016) Changing pattern of dengue virus serotypes circulating during 2008-2012 and reappearance of dengue serotype 3 may cause outbreak in Kolkata,India. J Med Virol 88: 1697-1702.

18. Geographical information of Sikkim. Sikkim.nic.in

19. Lancoitti RS, Calisher CH, Gubler DJ, Chang GJ, Vordnam AV (1992) Rapid detection and typing of Dengue viruses from the clinical samples by using Reverse Transcriptase Polymerase Chain Reaction. J Clin Microbiol 30: 545-551

20. Myers RM, Varkey MJ, Reuben R, Jesudass ES. (1970) Dengue outbreak in Vellore, Southern India, in 1968, with isolation of four Dengue types from man and mosquitoes. Indian J Med Res 58: 24-30.

21. Kumarasamy V, Wahab AH, Chua SK, Hassan Z, Chem YK, et al. (2006) Evaluation of a commercial dengue NS1 antigen capture ELISA for laboratory diagnosis of acute dengue virus infection. J Virol Methods 140: 75-79.

22. Ukey PM, Bondade SA, Paunipagar PV, Powar RM, Akulwar SL (2010) Study of seroprevalence of Dengue fever in Central India. Ind J Comm Medi 35: 517-519.

23. Gupta E, Dar L, Kapoor G, Broor S (2006) The changing epidemiology of Dengue in Delhi, India. Virol J 3: 92.

24. Chakravati A, Kumaria R (2005) Eco epidemiological analysis of Dengue infection during an outbreak of Dengue fever, India. Virol J 2: 32.

25. Hati AK, Bhattacharjee I, Mukherjee H, Bandyopadhayay B, Bandyopadhyay, et al. (2012) Concurrent Dengue and Malaria in an area in Kolkata. Asian Pac J Trop Med 5: 315-317.

26. Gunasekaran P, Kaveri K Mohana S, Arunagiri K, Suresh Babu BV, et al. (2011) Dengue disease status in Chennai (2006-2008): A retrospective analysis. Indian J Med Res 133: 322-325.

27. Gibbons RV, Vaughen DW (2002) Clinical review dengue. An escalating problem, BMJ 324: 1563 .

28. Barauh HC, Mahanta J (1996) Serological evidence of DENV 2 activity in Assam and Nagaland. J Commun Dis 28: 56-58.

29. Mahadev PV, Kollali VV, Rawal ML, Pujara PK, Shaikh BH, et al. (1993) Dengue in Gujarat state, India during 1988 and 1989. Indian J Med Res 97: 135-144.

30. Gupta N, Srivastava S, Jain A, Chaturvedi UC (2012) Dengue in India. Indian J Med Res 136: 373-390.

31. Dar L, Broor S, Sengupta S, Xess I, Seth P (1999) The first major outbreak of Dengue hemmorhagic fever in Delhi, India. Emerg Infect Dis 5: 589-590.

32. Barde PV, Shukla MK, Kori BK, Chand G, Jain L, et al. (2015) Emergence of dengue in tribal village of Mandla district, Madhya Pradesh, India. Indian J Med Res 141: 584-590.

33. Anoop M, Issac A, Mathew T, Philip S, Kareem NA, et al. (2010) Genetic characterisation of Dengue virus serotype causing concurrent infection in an outbreak in Emakulam, Kerela, South India. Indian J Exp Biol 48: 849-857.

34. Bharaj P, Chahar HS, Pandey A, Diddi K, Dar L, et al. (2008) Concurrent infections by all four Dengue virus serotypes during an outbreak of Dengue in 2006 in Delhi, India. Virol J 9: 5-1.

35. Cecilia D, Kakade MB, Bhagat AB, Vallentyne J, Singh A, et al. (2011) Detection of Dengue 4 virus in Pune, western India after an absence of 30 years, its association with two severe cases. Virol J 8: 46.

36. Dash PK, Sharma S, Srivastava A, Santosh SR, Parida MM, et al. (2011) Emergence of Dengue virus type 4 (genotype 1) in India. Epidemiol infect 139: 857-861. 
Citation: Bhutia KD, Bhutia PY, Sharma T, Gurung S (2018) A Study on the Epidemiological and Serotype Pattern of Dengue Outbreak in Sikkim. J Trop Dis 7: 291. doi:10.4172/2329-891X.1000291

Page 4 of 4

37. Barde PV, Golbole S, Bharti PK, Chand G, Agarwal M, et al. (2012)

Detection of dengue virus 4 from central India. Indian J Med Res 136: 491-494. 